\title{
Examining Knowledge Transfer Activities in UK Universities: Advocating A PROMETHEE Based Approach
}

\author{
Ishizaka, Alessio \\ NEOMA Business School, 1 Rue du Maréchal Juin - BP 215 - 76130 Mont-Saint-Aignan \\ Cedex - France, Email: Alessio.ISHIZAKA@ neoma-bs.fr \\ Pickernell, David \\ Portsmouth Business School, University of Portsmouth, Email: david.pickernell@ port.ac.uk \\ Huang, Shuangfa \\ Portsmouth Business School, University of Portsmouth, Email: shuangfa.huang1 @ port.ac.uk \\ Senyard, Julienne \\ Griffith Business School, Griffith University, Nathan campus, Email: \\ j.senyard@griffith.edu.au|
}




\title{
Examining Knowledge Transfer Activities in UK Universities: Advocating A PROMETHEE Based Approach
}

\begin{abstract}
Purpose: The purpose of this study is to examine the portfolio of Knowledge Transfer (KT) activities in 162 UK higher education institutions. In doing so, this study creates an index and ranking, but more importantly, it identifies specific groupings or strategic profiles of universities defined by different combinations and strengths of the individual KT activities from which the overall rankings are derived. Previous research, concentrating on entrepreneurial universities, shows that individual knowledge transfer (KT) activities vary substantially among UK universities. The broad portfolio of universities' KT activities, however, remains underexplored, creating gaps in terms of the relative strength, range, focus, and combination of these activities, and the degree to which there are distinct university strategic KT profiles. By examining KT activities and grouping universities into KT "types", this research allows universities and policymakers to better develop and measure clearer KTstrategies.
\end{abstract}

Design/Methodology: The present study applied the Preference Ranking Organization Method for the Enrichment of Evaluations (PROMETHEE) to rank universities based on their portfolio of KT activities. It utilised data from the 2015-2016 Higher Education Business and Community Interaction Survey dataset.

Findings: Findings show that universities differ substantially in their portfolios of KT activities. By using PROMETHEE, a new ranking of universities is generated, based on their KT portfolio. This paper also identifies four distinct types or groups of universities based on the diversity and intensity of their KT activities: Ambidextrous, Broad, Focused, and Indifferent. 
Originality/Value: The study contributes to the entrepreneurship literature, and more specifically entrepreneurial activities of universities through new knowledge generated concerning university KT activity. The research extends the existing literature on university archetypes (including those concerned with the Entrepreneurial University) and rankings using a new technique that allows for more detailed analysis of the range of university KT activities. By applying the PROMETHEE approach, results illustrate a more nuanced definition of university KT activities than before, by simultaneously evaluating their overall strength, range, focus, and combination, allowing us to identify the universities' strategic profiles based on their KT portfolios. Implications of the findings for key stakeholders include a potential need for government Higher education policymakers to take into account the different mixes of university archetypes in a region when considering how best to support higher education and its role in direct and indirect entrepreneurship promotion through regional policy goals.

Keywords Entrepreneurial University, Knowledge Transfer Activities, PROMETHEE, University Ranking. 


\section{Introduction}

The knowledge transfer practices of universities, particularly in entrepreneurial and regional contexts, have garnered increased interest in recent discourse (see for example Martin et al., 2019; Pittaway et al, 2019; Fuller et al., 2018; Culkin, 2016). Knowledge transfer (KT) activities, also known as third mission activities or entrepreneurial activities (Philpott et al., 2011; Berbegal-Mirabent et al., 2013), are in the UK measured under the term Third Sector Activity (TSA). Universities are under increasing pressure to engage in greater KT activities (Gulbrandsen and Slipersaeter, 2007) to tackle the challenges of the knowledge economy more directly (Charles et al., 2014; Miller et al., 2014), contribute to economic and social development (Perkmann et al., 2013; Sánchez-Barrioluengo, 2014), and mitigate decreasing higher education funding from government (Mowery et al., 2015).

The role of universities has generated growing interest among academics and policymakers in the "Entrepreneurial University" (Etzkowitz et al., 2000; Guerrero et al., 2016) concept. In this context, the concept describes universities who engage in third-mission activities that enhance the performance of the regional or national economy and their financial position (Etzkowitz et al., 2000). KT activities, for example, can contribute to regional economic development through the creation of new ventures and jobs (Fini et al., 2011). They also directly contribute to society via the introduction of new products and services (Colyvas, 2007).

While research has started to explore how KT activities vary between universities, prior studies tended to follow relatively narrow, usually dichotomous, evaluations, such as 'elite' (Research and Development, technology transfer and new firm development focused) and 'outreach' (firm embedding, education and training, social capital and networking for regional economic development) universities (Morgan, 2002), or low research-intensive and high researchintensive universities (Hewitt-Dundas, 2012). Recent evidence in the context of university 
ambidexterity suggests that universities' past research output (both quality and quantity) positively impact their knowledge transfer activities (Sengupta and Ray, 2017a), but this effect is mitigated by the reputational effects of, in the $\mathrm{UK}$, for example, their Russell Group status. Nevertheless, more recent work has also adopted this essentially dichotomous approach. Fuller et al. (2018), for example, construct indexes based on universities existing along (indexed) dichotomous continuums in terms of the extent to which they can be seen as more "entrepreneurial" (defined by their concentration on a range of activities primarily for their own benefit) or "enterprising" (more balanced in their focus in activities that benefit both themselves but also the economy more widely).

Additionally, analysis of the full mix of KT activities that universities actually pursue has received relatively limited attention (Sengupta and Ray, 2017b). Existing studies tend to focus on individual KT activities without considering the full portfolio of KT activities pursued by universities (Hewitt-Dundas, 2012; Abreu et al., 2016). Even where multiple KT activities have been analysed together, as in Fuller et al., (2018), analysis has concentrated on the overall resulting index score and university ranking, rather than analysing the range of ways in which similar rankings may be achieved by universities exhibiting different KT activity profiles. While evidence suggests universities are strategic in the KT activities they pursue (Day and Fernandez, 2015; Kitagawa et al., 2016), how universities differ in their KT activities profiles also remain unclear.

Consequently, there are gaps in the research in terms of the relative strength, range, focus, and combination of KT activities, and the degree to which there are distinct university strategic KT profiles. The purpose of this paper, therefore, is to examine KT activities and also to group universities into KT “types”, allowing universities to better develop and measure KT strategies, and allow policymakers a better understanding on the ways to best support universities through policies and programs. 
To develop this more nuanced understanding of the KT activities universities pursue, this study simultaneously analyses the size, scope, and focus of universities' KT portfolios using a novel methodological approach based on the Preference Ranking Organization Method for the Enrichment of Evaluations (PROMETHEE). Using multiple criteria, PROMETHEE allows us to rank universities according to their portfolios of KT activities whilst simultaneously identifying and illustrating groups of universities sharing similar KT portfolios. In other words, using PROMETHEE can uncover the different types or groups of universities based on their overall KT activities.

Using the 2015-2016 Higher Education Business and Community Interaction Survey (HEBCIS) dataset, this research identifies, where possible, universities' incomes from each KT activity they pursue, to proxy for their relative strategic focus on each KT activity. Where this was not possible, other available measures (e.g. attendance at paid activities) were used. As a result, the research helps to institutionalise universities' third-mission KT activities, through the value derived from objective measurement, to not only rank universities but also to group them into identified types beyond the more traditional dichotomous rankings.

The study contributes to the entrepreneurship literature, and more specifically entrepreneurial activities of universities, through its analysis of university KT activity, extending the existing literature on university archetypes, including those concerned with the Entrepreneurial University. The study also makes an overlapping contribution to the current understanding of KT within universities in the UK context resides in using the PROMETHEE-based approach to evaluate universities' overall strength, range, focus, and combination of KT activities, thus allowing us to identify universities' strategic profiles based on their KT portfolios. This extends the existing literature on university archetypes and rankings through more detailed analysis of the range of university KT activities. The paper also provides a contribution to understanding KT processes within universities by identifying which combinations of KT activities are most 
complementary or substitutive. This is potentially important for resource-constrained universities. The UK context has been chosen because of previous research conducted in this area, the variables available in the HE-BCIS dataset, and also because, through the proposed KEF framework, these issues are likely to become more important in the future for UK universities (see, for example, Johnson, 2020).

The rest of the paper is structured as follows. First, the existing literature for university KT activities is reviewed in terms of the different types of activities they can engage with, from which research questions are developed. Second, the PROMETHEE-based methodology is introduced, followed by the results. After that, the results are analysed in relation to the research questions and discussed and compared with the existing literature. Finally, in the conclusions, contributions are identified, limitations explained, and future research opportunities discussed.

\section{Theoretical development}

\subsection{The diversity and intensity of knowledge-transfer activities}

Extensive research has shown that universities use a wide range of channels for KT activities (D'Este and Patel, 2007; Perkmann et al., 2013; Abreu et al., 2016). KT activities can be categorised into research commercialisation and academic engagement (Perkmann et al., 2013). Research commercialisation refers to activities such as spin-outs, patenting and licensing activities to commercialise universities' intellectual properties. While researchers have devoted substantial attention to these activities (Czarnitzki et al., 2009; Fini et al., 2011; Magerman et al., 2015), evidence suggests they account for only a relatively small proportion of all KT activities pursued by universities (Schartinger et al., 2001; HEFCE, 2017). Academic engagement concerns activities including consultancy, contract research, collaborative research, training, and facilities-related services. They play a dominant role in the interactions between universities and industry (Huggins et al., 2012; Hughes and Kitson, 2012; Abreu and 
Grinevich, 2013). Indeed, the majority of universities' KT-related incomes are generated through activities in relation to academic engagement (HEFCE, 2017).

The extent of universities' KT activities can be captured through two aspects: diversity and intensity (Hughes and Kitson, 2012; Iorio et al., 2017). The diversity of KT activities concerns the range or number of different $\mathrm{KT}$ activities universities pursue. Some universities, for example, pursue a wide range of KT activities, whereas others tend to focus on a smaller number of such activities (Sengupta and Ray, 2017b). That is, universities may exhibit a broad or focused KT portfolio. A broad approach allows universities to generate revenues from diverse sources. The reason is that, all other things being equal, diverse KT channels allow universities to address the different needs of organisations (Olmos-Peñuela et al., 2014). Furthermore, it provides access to the diverse knowledge base of industry practitioners (D'Este and Patel, 2007; Iorio et al., 2017). Yet, a broad KT portfolio requires internal processes and infrastructure to support the different KT activities (Guerrero and Urbano, 2012). A focused KT portfolio, by contrast, allows universities to concentrate on areas where they have greater strengths (Day and Fernandez, 2015).

The intensity of KT activities concerns the prominence of each activity for the universities. Among the different KT activities universities pursue, for example, some activities may have great importance (Day and Fernandez, 2015). Likewise, some KT activities may be used by universities more often to intensely interact with industries (Huggins et al., 2012). Indeed, evidence suggests universities are likely to emphasise certain KT activities over others (Berbegal-Mirabent et al., 2013), with Secundo et al (2017) highlighting three distinct, though overlapping, areas in terms of research (technology transfer and innovation), teaching, (lifelong learning and continuing education), and social engagement (regional and national development), which clearly overlap with the missions of universities. As a result, KT activities, for most universities, are likely to differ in their levels of intensity. 


\subsection{The determinants of KT activities}

The portfolio of KT activities pursued by universities is expected to vary for several reasons. First, universities have different objectives and strategic focus (Bronstein and Reihlen, 2014; Sengupta and Ray, 2017b). Literature suggests some universities are research-driven, while others are industry-driven, and a third group are oriented toward knowledge commercialisation (Bronstein and Reihlen, 2014), whilst Cesaroni and Piccaluga (2016) in the Italian context find different clusters determined by their degree of focus on research and / or KT. Because of the different strategic focus, universities often emphasise activities that are aligned with their objectives. It has been found that around $46 \%$ of all higher education institutions (HEIs) in the UK emphasise research collaboration with industry as a key area to generate economic impact, whereas only $8 \%$ of HEIs emphasise areas such as spin-out activity or licensing (HEFCE, 2017).

Second, universities differ in their backgrounds with respect to scientific disciplines. Prior research has shown that universities with more applied disciplines, such as engineering or biotechnology, are more likely to pursue formal commercial activities (Perkmann et al., 2013). Similarly, Van Looy et al., (2011) found that the presence of an engineering department contributes to the number of patent activities within a university. Kalar and Antoncic (2015) identified higher entrepreneurial perception in the natural sciences than in the social sciences, whilst, Abreu and Grinevich (2013) observed that academics in different disciplines often engage in different KT activities. Specifically, academics in engineering, the natural sciences, and the biological sciences have a higher tendency to pursue formal commercial activities such as spin-outs and licensing activities, whereas those in the humanities and social sciences are more likely to engage in informal commercial activities. These empirical works suggest the backgrounds of universities are likely to influence their portfolio of KT activities. 
Third, universities differ in their resources and capabilities, implying they may pursue KT activities that best fit with their strength and capabilities (Kitagawa et al., 2016). In the UK, for example, Russell Group universities possess more resources in terms of human capital, financial, and physical resources than other universities (Russell Group, 2015). Resource availability determines their capacity to pursue KT activities. University size, as captured by the number of academic staff, for example, influences levels of patenting and contract research activities (Van Looy et al., 2011). Russell Group universities also have greater research capabilities with respect to higher numbers and quality of research outputs than other universities. The research capability may translate into research outputs that can be used for knowledge transfer. Indeed, evidence suggests universities' past research output is positively related to their levels of engagement in different KT activities (Van Looy et al., 2011; Sengupta and Ray, 2017a). While universities may focus on areas where they have strength, they can, however, also choose activities based on their future strategic direction and as a result, establish new capabilities.

It is also important to consider the regions in which universities are embedded because the numbers, sectors, and growth ambitions of firms tend to differ between regions (Mason and Brown, 2013). Indeed, research has shown that a favourable environment in the region can influence the types of KT activities universities pursue (Berbegal-Mirabent et al., 2015), although Martinelli et al (2008) also highlight that the majority of a university's partners may not be located in their own region even where that region is highly developed. Broadly, however, universities in different regions tend to see variance in the local demand for KT activities that, in turn, may influence their KT portfolio, and their own regional policy engagement approach (Molas-Gallart and Castro-Martínez, 2007).

Finally, at a national level, policies such as the Teaching Excellence Framework (TEF) and the Research Excellence Framework (REF) have had a substantial influence on universities' KT 
activities (Abreu et al., 2016; Gourlay and Stevenson, 2017). Consequently, universities are facing greater pressure to balance their different activities in relation to teaching, research, and third mission.

This review of the literature, therefore, identifies a range of relationships between universities and their KT activity. Using the existing literature, which often uses basic, dichotomous relationships in its analysis, leads to the following four broader, research questions:

Based on the work of Abreu et al. (2016) related to the relationship between KT and their other two missions of research and teaching: How do universities valorise university knowledge assets in terms of the most beneficial KT activities? (RQ1)

Based on the work of Perkmann et al. (2013) related to research commercialisation and academic engagement: Which university models/archetypes can be identified and classified in terms of these KT activities? (RQ2).

Based on the work of Hewitt-Dundas (2012) related to high research-intensive university activities: What are the most relevant KT activities (both singular and in combination) that universities are using? (RQ3)

Based on the work of Morgan (2002) related to outreach and research-intensive dichotomies: What are the relationships between specific university models/archetypes and university regional economic development policy? (RQ4)

\section{Methodology}

The methodology is based on three steps. First, the Preference Ranking Organization Method for the Enrichment of Evaluations (PROMETHEE) is used to rank the universities (Brans and Vincke, 1985; Brans, 1982). Then Graphical analysis for interactive aid (GAIA) is used to 
visually identify a number of different university groupings that exist regarding their strategic mixes. Then, alternatives which have the same preferred strategic focus are grouped together mathematically.

PROMETHEE offers several advantages to examine the KT activities of universities. First, it employs visualisation software that, with a few parameters, creates non-technical, user-friendly visualization of results (Brans, 1982; Brans and Vincke, 1985; Nemery et al., 2012). Second, it utilises the natural units to express and evaluate each criterion, meaning that it eliminates problems due to scaling, obviating the need for the normalization of scores, avoiding rankings that rely on the selected normalization method (Tofallis, 2008; Ishizaka and Nemery, 2011) or the log-based approach highlighted in Fuller et al., (2018). Instead, the decision-maker defines a preference function generally characterised by an indifference and preference threshold. Third, the partial compensatory quality of PROMETHEE offers policymakers and universities an improved way for measuring the full range of KT-activities, in order to better determine which KT-strategy combinations are most suitable. Importantly, PROMETHEE is also able to link to graphical analysis for interactive aid (GAIA), allowing two-dimensional representation of individual decision-maker preferences (Brans and Mareschal, 1994). In this research, all included universities can be represented and then compared on a single GAIA diagram, which compares favourably to previous approaches (for example, Fuller et al., 2018) which require multiple diagrams to undertake the same types of processes. Overall, therefore, the use of PROMETHEE and GAIA, can help institutionalise the third mission of universities.

\subsection{PROMETHEE}

PROMETHEE (Brans and Vincke, 1985; Brans, 1982) has been used to solve several case studies (Behzadian et al., 2010; Lai and Ishizaka, 2019). Its popularity is due to readily available software, such as SmartPicker (Nemery et al., 2012), and Visual PROMETHEE 
(Ishizaka et al., 2018) and D-Sight (Hayez et al., 2012), which can be used easily. In PROMETHEE, normalisation is not needed, which means that scores on each criterion can be given in their natural units. This property has the advantage of avoiding any scaling effect problem, which indicates that a ranking is dependent on the selected normalisation method (Ishizaka and Nemery, 2011; Tofallis, 2008). The only inputs the decision-maker requires are the weighting of the criteria and the preference function, which are generally defined by an indifference and preference threshold.

Preferences at Criterion level - The modelling of the problem is done by defining a set of $m$ possible actions or alternatives $A=\left\{a_{1}, a_{2}, \ldots, a_{m}\right\}$ which need to be evaluated on a set of $n$ criteria $C=\left\{c_{1}, c_{2}, . ., c_{n}\right\}$. A preference function is defined on each criterion, which measures the preference degree $P_{i}(a, b)$ between each pair of actions. Several types of preference functions exist, such as the linear, the step, or Gaussian preference function (Brans and Vincke, 1985).

Aggregated Preference Functions- The preference index $\pi(a, b)$ indicates how much action $a$ is preferred to $b$ over all the criteria. It is calculated with a weighted sum (1) of the preference degrees $P_{i}(a, b)$. The weights $w_{i}$ represent the importance of each criterion in the decision.

$$
\pi(a, b)=\sum_{i=1}^{n} P_{i}(a, b) \cdot w_{i}
$$

where $P_{i}(a, b)$ is the score of the preference function, $w_{i}$ the weight of criterion $c_{i}$ and $n$ the number of criteria.

Outranking Flows- Based on all the comparisons with the other $m-1$ actions, two flows can be defined with (1):

The Positive flow: 
(2) $\Phi^{+}(a)=\frac{1}{m-1} \sum_{x \in A}^{m} \pi(a, x)$

where $m$ is the number of actions of the set $A$

This score represents the global strength of action $a$ over all the other actions. The higher the global strength, the better the action is.

The Negative flow:

(3) $\quad \Phi^{-}(a)=\frac{1}{m-1} \sum_{x \in A}^{m} \pi(x, a)$

where $m$ is the number of actions of the set $A$

This score represents the global weakness of $a$ against all the other actions. The lower the global weakness, the better is the action.

Ranking- The complete ranking of PROMETHEE II is given by the net flow:

$$
\Phi(a)=\Phi^{+}(a)-\Phi^{-}(a)
$$

The higher the net flows, the better the rank of an action. A fuller discussion on net flow scores can be found in Brans \& Mareschal (2005) and Mareschal, De Smet, \& Nemery (2008).

\subsection{Visualizing the results}

The Graphical analysis for interactive aid (GAIA) method is a technique to represent on a plane as much information as possible (Brans and Mareschal, 1994). To have a two-dimensional view, a plane in the hyperspace is found via principal component analysis (PCA) of the matrix $\Phi$. The PCA is calculated with the variance-covariance matrix of the decision problem, noted as $\mathrm{C}$ and obtained from:

$$
n \mathrm{C}=\Phi^{\prime} \Phi
$$

...where

$\mathrm{C}$ : variance-covariance matrix 


\section{$\Phi$ ': the transposed matrix of $\Phi$ \\ $n:$ positive integer}

Then, the two eigenvectors $\vec{u}$ and $\vec{v}$ corresponding to the greatest eigenvalues $\lambda_{1}$ and $\lambda_{2}$ are selected. These two eigenvectors are orthogonal $(\vec{u} \perp \vec{v})$ and define the best plane, which will minimize the loss of information when the actions $a_{i}$ are projected on it. (Brans and Mareschal, 1994).

The coordinates of the actions are obtained as follows:

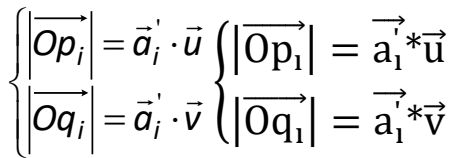

...where $\vec{a}_{i}^{\prime}$ : transposed row $i$ of matrix $\Phi$

In order to represent the intra-criteria information, each criterion $f_{j}$ will be projected to $c_{j}$ on the GAIA plane. The measure of similarity or dissimilarity between the criteria is given by the angle between the projections of two criteria. A small angle means a high similarity. A large angle indicates dissimilar or conflicting criteria.

The weights chosen by the decision-maker can also be seen on the GAIA plane by adding the projection of the weights vector: $\overrightarrow{\mathrm{w}}:\left(\mathrm{w}_{1}, \mathrm{w}_{2}, \ldots, \mathrm{w}_{\mathrm{j}}, \ldots, \mathrm{w}_{\mathrm{k}}\right)$. The obtained vector is called a Decision Stick, $\vec{D}$, and represents the decision-maker's priorities:

$$
\vec{D}:(\vec{w} \cdot \vec{u}, \vec{w} \cdot \vec{u})
$$

The GAIA plane aids the decision-making process by assisting conclusions that can be drawn from the visually presented data. Specifically, near actions on the plane imply similar scores and behaviour, allowing decision-makers to easily identify actions with similar or dissimilar performance. The decision-maker can also compare criteria, since their direction on the plane 
indicates similar or conflicting behaviour. In addition, the length of the criterion also helps identify differences in distinguishing power, with a wash criterion having a short length and a discriminating criterion having a long length.

\subsection{Grouping}

The grouping analysis has two phases. The first phase groups the actions with a negative net flow. These actions lag behind and cannot be taken as exemplars. In the second phase, the number of clusters needs to be decided for group actions with a positive net flow. This decision is informed by the GAIA plane, where the groups can be seen visually. Then, for each group, a typical action is selected. This choice is again supported by the GAIA plane. In order then to classify the other actions, the degree of correlation is used, which is different from distancebased clustering. The Pearson correlation between action $\mathrm{X}$ and $\mathrm{Y}$ is given by:

$$
r_{X Y}=\frac{\sum_{i=1}^{n}\left(X_{i}-\bar{X}\right)\left(Y_{i}-\bar{Y}\right)}{\sqrt{\sum_{i=1}^{n}\left(X_{i}-\bar{X}\right)^{2}} \sqrt{\sum_{i=1}^{n}\left(Y_{i}-\bar{Y}\right)^{2}}}
$$

\subsection{Data used}

The UK context has been chosen because there is a concentration of research (previously discussed) that was conducted in the UK and against which this research can be compared, because of the relatively extensive data available from the HE-BCIS dataset, and because the UK government's proposed KEF framework means that KT-related issues are likely to become even more important in the future for UK university strategists. As identified in Fuller and Pickernell (2018), the HE-BCIS is also regarded as the most comprehensive dataset available to researchers, allowing other countries seeking to adopt similar survey methods to gain a better understanding of their own universities' KT activities.

In terms of the variables used, they are all taken from the 2015-2016 HE-BCIS dataset, with all but one of them expressed in $£$, the exception being for chargeable events where numbers 
of attendees were the measure used. Nine variables are used, capturing various aspects of universities commercial / income generating KT activities discussed in the literature, as follows:

- Attendees at Chargeable Events

- Income from Continuous Professional Development

- Income from Shares sold in Spin-outs

- Income from Regeneration and Development Programmes

- Income from Consultancy

- Intellectual Property (IP) Income

- Income from Collaborative Research

- Income from Contract Research

- Income from Facilities and Equipment Related Services

These variables represent only a sub-set of the potential KT and related activities of universities, and there are limitation to how well they capture the diversity of KT-activities at universities. For example students (and indeed staff) engaging in entrepreneurship, outreach, venture creation or collaboration projects, may also be considered important KT-activities. The selection of variables in this paper is based on the work of Fuller and Pickernell (2018), which found that, looking at the widest range of university TSA, 4 groups of KT activities could be identified. Three of the four groups they identified were less directly related to the university itself, namely "Staff Spin-off Activity", "Non-HEI Owned Spin-Off Activity" and "Graduate Start-up Activity". The remaining factor, named "University Knowledge Exploitation Activity (UKEA)" included a broad range of university knowledge creation, exchange and exploitation activities, which can most easily be related to KT. The paper extends this prior work by focusing on activities where the university itself was directly capturing value from its KT activities, providing a more fine grained analysis. Also, given the Fuller et al's (2018) dichotomy of continuums based on the extent to which a university can be seen as more “entrepreneurial", defined by concentration on a range of activities more likely primarily for their own benefit, and enterprising (more balanced in their focus in activities that both benefit 
themselves but also the economy more widely). The results in this paper can also be viewed in this context.

\section{Results}

The results are presented in a number of ways. First, and most easily comparable with previous studies, is through indexing University KT Activity. Based on the PROMETHEE analysis Table 1, for reasons of brevity, shows the first 30 universities in the index.

\section{Table 1 PROMETHEE Based University Ranking}

\begin{tabular}{clccc}
\hline Rank & University & Positive & Negative & Net Flows \\
\hline 1 & A25-The University of Cambridge & 0.361 & 0.007 & 0.354 \\
2 & A104-The University of Oxford & 0.302 & 0.011 & 0.291 \\
3 & A28-Cardiff University & 0.232 & 0.018 & 0.214 \\
4 & A134-The University of Southampton & 0.221 & 0.016 & 0.205 \\
5 & A93-The University of Manchester & 0.216 & 0.014 & 0.202 \\
6 & A150-University College London & 0.213 & 0.016 & 0.197 \\
7 & A75-The University of Leeds & 0.199 & 0.024 & 0.176 \\
8 & A48-The University of Edinburgh & 0.186 & 0.019 & 0.168 \\
9 & A13-The University of Birmingham & 0.186 & 0.025 & 0.162 \\
10 & A67-Imperial College & 0.166 & 0.024 & 0.143 \\
11 & A70-King's College London & 0.152 & 0.018 & 0.135 \\
12 & A44-The University of East Anglia & 0.142 & 0.024 & 0.118 \\
13 & A102-The Open University & 0.135 & 0.033 & 0.102 \\
14 & A100-University of Nottingham & 0.120 & 0.021 & 0.100 \\
15 & A132-The University of Sheffield & 0.122 & 0.025 & 0.097 \\
16 & A55-The University of Glasgow & 0.113 & 0.021 & 0.092 \\
17 & A152-The University of Warwick & 0.111 & 0.021 & 0.090 \\
18 & A139-The University of Strathclyde & 0.109 & 0.023 & 0.085 \\
19 & A36-Coventry University & 0.108 & 0.023 & 0.084 \\
20 & A26-The Institute of Cancer Research & 0.118 & 0.047 & 0.071 \\
21 & A95-Newcastle University & 0.097 & 0.026 & 0.070 \\
22 & A89-London School of Economics \& Political Science & 0.093 & 0.026 & 0.067 \\
23 & A4-Anglia Ruskin University & 0.094 & 0.029 & 0.065 \\
24 & A10-The Queen's University of Belfast & 0.088 & 0.026 & 0.062 \\
25 & A85-London Business School & 0.100 & 0.041 & 0.059 \\
26 & A91-Loughborough University & 0.087 & 0.028 & 0.059 \\
27 & A120-The Royal Central School of Speech and Drama & 0.104 & 0.046 & 0.058 \\
28 & A82-The University of Liverpool & 0.079 & 0.028 & 0.051 \\
29 & A109-Queen Mary University of London & 0.080 & 0.029 & 0.051 \\
30 & A77-The University of Leicester & 0.072 & 0.026 & 0.046 \\
\hline & & & & \\
\hline
\end{tabular}


This ranking generates an order consistent with previous work (albeit in slightly different contexts using different methods) conducted by, for example, Fuller et al., (2018). However, because PROMETHEE is specifically designed to focus on the portfolio of activities employed via the way in which the scores are generated, and supported by the additional visualisation techniques employed via GAIA, the additional relevant information is also both generated and visually presented as discussed below.

Figure 1 illustrates the ranking of universities, using the net value (positive and negative flows), as shown in Table 1. The stacked bar chart indicates how each of the criteria used (e.g., KT activity) contributes to the overall score (which, again for brevity, only shows the first 30 universities in the index). Because PROMETHEE is a partial compensatory method, however, low scores for one or more variables cannot be fully compensated by high scores by another variable, whilst reliance on one or a small number of variables is also partially compensated for. 


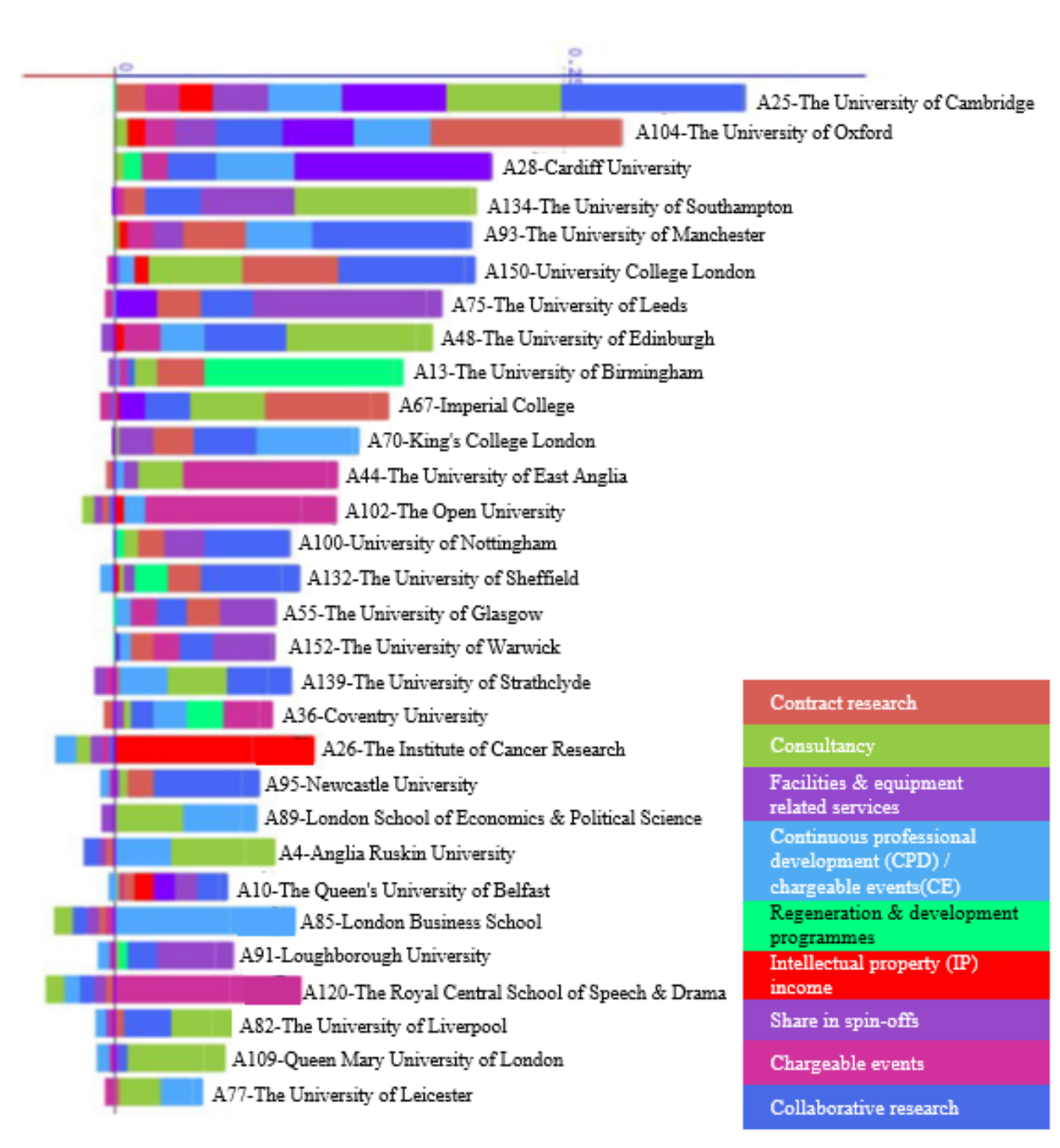

\section{Figure 1: University ranking based on KT portfolio}

For example, the London Business School (A85) score is both very strong but also very reliant on $\mathrm{CPD} / \mathrm{CE}$ income and would appear higher in the rankings without PROMETHEE being able to partially compensate for this (with indifference thresholds defining the minimum required for a criterion to begin acquiring positive values, and preference thresholds identifying the maximum value that can be obtained from this positive flow). This therefore partially compensates in the overall ranking for universities concentrating only or mainly on that measured criteria. An overall negative score means the University is, below the broad average, whilst a positive score indicates an above average overall performance. 
In general terms, this allows identification of a university's relative KT strengths (which could be used for marketing purposes) and weaknesses (that could be used to focus future policy action) by each university. London Business School (A85), for example, would improve its ranking if they could improve on the consultancy income they could generate (though of course, this may not be a focus for strategic reasons, as will be discussed later). Many universities, however, have a very small bar, which, assuming this is in line with their strategic goals (discussed in more detail later), indicates a need to improve their performance in all criteria used in the analysis.

The GAIA visual technique also provides additional information to that generated for ranking through the identification of the criteria contributing most to the ranking differences between universities. Specifically, it identifies where criteria are more closely correlated with each other. GAIA is also a visual means of identifying groupings of universities as defined by similar outcomes from universities' KT portfolio.

Figure 2 shows the GAIA plane. Chargeable events, $C P D-C E$ and Collaborative research have the longest arrows, implying they have the best discriminating power for evaluating Universities. The criteria IP income, share in spin-outs, and regeneration and development programmes, in contrast, have low discriminating power (shorter arrows), which indicates that universities have very similar values for these activities, with many universities not undertaking these activities at all. For the first two of these criteria, in particular, often seen as key to the "entrepreneurial university" paradigm, this shows that such activities are not as useful as others in allowing comparison between universities, though, as shall be seen later, for the highestranked universities, they also constitute an important element of universities' overall activities. 


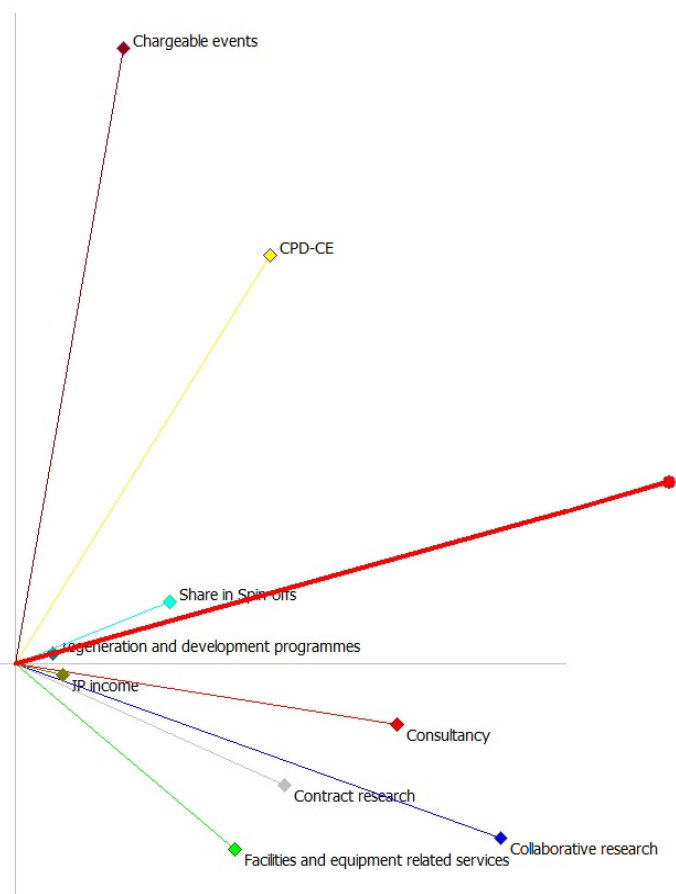

\section{Figure 2: The GAIA plane analysis for knowledge transfer activities}

As all the arrows are pointing to the right of the vertical axis, this indicates that the criteria are all positively correlated. The closer the lines are to each other, the stronger the correlation. Facilities and equipment-related services, contract research, collaborative research, and consultancy are therefore strong for their discriminating power and are strongly correlated with each other, illustrating that universities concentrating on these activities simultaneously employ a mixture of TSAs.

In contrast, the arrow for two types of more local "soft" activities, namely, facilities and equipment-related services, stands $90^{\circ}$ different to chargeable events, indicating that universities generating strong income performance from facilities and equipment-related services do much less well in terms of chargeable events and vice versa. The greater the angles between the variables, the greater the possible tensions between policies concentrating on increasing the values of these variables, but with potential trade-offs required, since they are 
less strongly mutually supportive than where variables are more strongly correlated. The diagram below then shows how individual universities map onto these activities.

\section{Discussion}

\subsection{How universities generate value from their knowledge through KT activities}

Figure 2 shows the different ways in which universities generate value from their KT. The criteria having the best discriminating power between universities are those with the longest arrows. Figure 2 indicates, therefore, that the variables with the greatest differences between universities are Chargeable events, CPD-CE and Collaborative research. Figure 2 also highlights, through criteria that are closer to each other, that there are broad groups of variables that universities use to generate value. Most obviously, Figure 2 indicates that CPD-Chargeable Events function as one combination of knowledge assets, and Collaborative (with Facilities, contract and consultancy) as another. In answering RQ1, the results indicate that universities do indeed differ most in their ability to generate value from KT activities classified according to teaching (CPD-Chargeable Events) and research (with Facilities, contract, and consultancy) supporting the prior research of Abreu et al., 2016.

\subsection{The university models/archetypes that can be identified and classified in terms of these KT activities}

Figure 3 identifies where individual universities sit on the GAIA plane, both in terms of the activities they focus upon and the other universities to which they are closest. The precise position of each university in Figure 3 shows a combination of the strength (or weakness) in overall activities and also the activity/activities it is most strongly associated with. Broadly, the further from the axis the university is, the stronger are its activities; the closer to a specific activity, the more its overall score is related to that activity; the closer to another university, 
the more they are similar to that university in terms of range of activities. Given that there are multiple planes, however, this initial visual representation also needs to be supported by a further mathematical analysis (the correlation analysis discussed below).

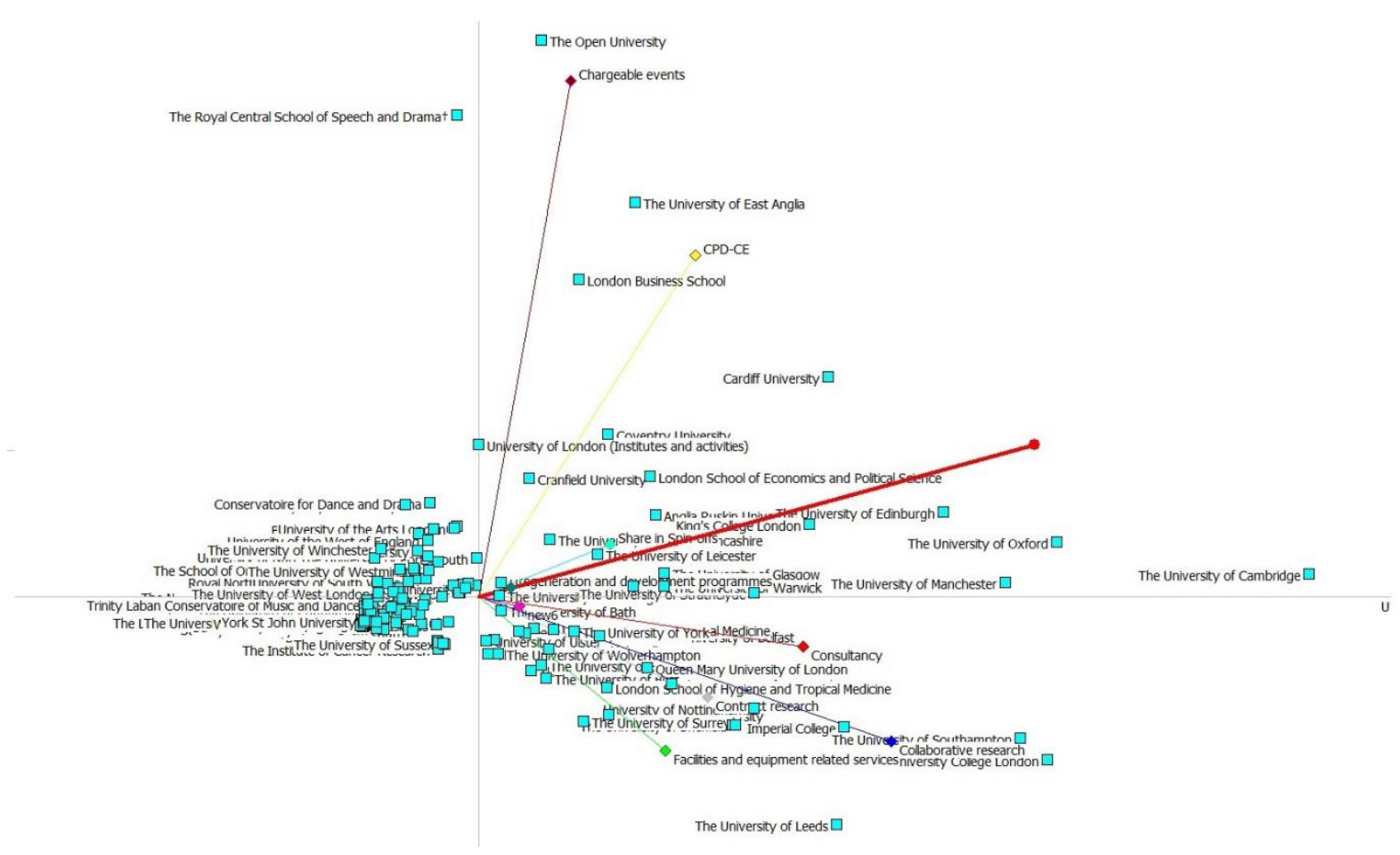

\section{Figure 3: Groupings of universities based on overall KT activities}

Using Figure 3, four different archetypal categories (groupings) of university models/archetypes can first be visually identified and classified in terms of these KT activities and their degree of concentration. These groupings are as follows:

- (In the right upper quadrant) CPD-Chargeable Events Grouping. The exemplar is the University of East Anglia).

- (In the right lower quadrant) Collaborative Grouping (with Facilities, contract and consultancy). The exemplar is Leeds University.

- (On the border of the right upper and lower quadrants) Research Grouping (with IP and share in spin-outs). The exemplar here is Cambridge University. 
- (To the left of the vertical plane) Weak External Entrepreneurial Income generating Activities Grouping (having negative values). The exemplar here would be the University of York and St John.

Answering RQ2 reveals Perkmann et al's (2013) dichotomy of models / archetypes of research commercialisation and academic engagement in terms of the Research-focused and Collaborative groupings respectively. An additional strong KT activity grouping (concentrating on CPD-Chargeable Events) can also be seen with regards to more teachingrelated activities, as well as a large group (with Weak External Entrepreneurial Income generating Activities) where KT activities generally are weak.

This analysis also shows that whilst these KT activities, used as a way of measuring third mission, are most closely associated with the Fuller and Pickernell (2018) concept of "entrepreneurial" (particularly the group concentrating on research activities). They can also be seen as relevant to the overlapping concepts of "engagement" (particularly the group concentrating more on CPD-Chargeable events) and "collaboration" (particularly the collaborative group).

After the groups have been visually identified on the GAIA plane, the universities that are identified within each group are classified via the strength of the correlations between their KT activities mix and that of the "exemplar" university in that grouping. Thus, using the analysis in the literature concerning the breadth and intensity of KT activities allows the creation of the following strategic framework (see Figure 4), representing the different groups or types of universities based on their KT portfolio.

- The Ambidextrous group, with both relatively high diversity and intensity of KT activities, is most strongly associated with the Research grouping. 
- The Indifferent group, with relatively low intensity and low diversity of KT activities, is most strongly associated with the group with Weak External Entrepreneurial Income generating Activities.

- The Focused group, where KT intensity is relatively high, but diversity is relatively low, is most strongly associated with the CPD-Chargeable Events focused grouping.

- The Broad group, where diversity is relatively high, but intensity is relatively low, is most strongly associated with the Collaborative grouping.

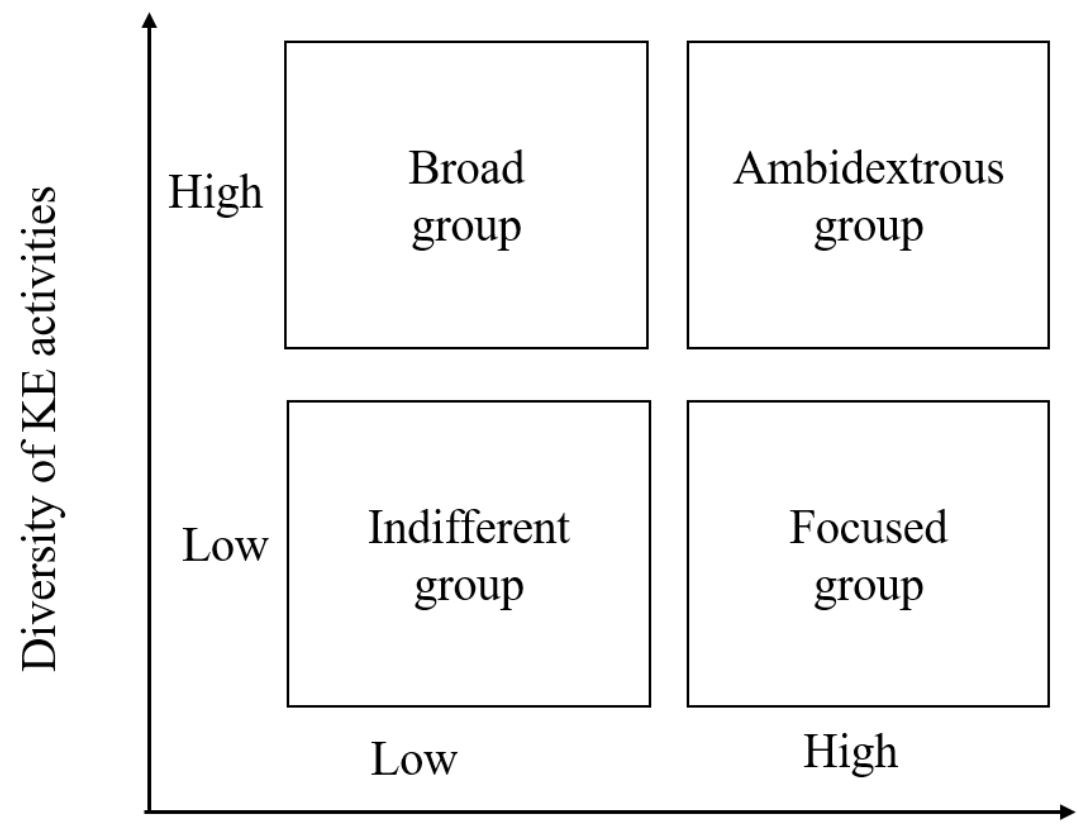

Intensity of KE activities

Figure 4: University type based on portfolio of KT activities

\subsection{The most relevant KT activities (both singular and in combination) that universities are pursuing}

RQ3 results highlight the foci of the groupings, and the most relevant KT activities (both singular and in combination) that universities are pursuing will be those related to the high research-intensive universities represented by the Russell group (supporting to an extent Hewitt-Dundas, 2012), although this is not a consistent pattern.. The high research-intensive 
universities that dominate the Ambidextrous grouping are the most likely to engage in KT through IP income, as well as in collaborative research partnerships (where co-production of knowledge is more likely to produce high-quality academic outputs) with greater discriminatory power between HEIs. Low research-intensive universities that dominate the Indifferent group are also consistently weaker in their activities, while collaborative research is, relative speaking, their strongest KT activity. Conversely, however, the other two groupings, indicate a more nuanced picture than has hitherto been presented in prior research.

Using these groupings then allows us to identify the most relevant KT activities (both singular and in combination) that universities pursue, specifically in terms of the rankings that each group achieves. The Ambidextrous universities, with specific strength in IP and spin-outs, are more likely to be found more often and higher up the top 20 of the Entrepreneurial University rankings (included in the top five rankings are Cambridge University (1st), Cardiff (3rd), Southampton (4th), and Manchester (5th)). Overall, 11 of the top 20 places are taken by universities with this type of focus, compared to four in the collaborative Broad universities group, and three in the more narrowly (CPD-Chargeable Events) Focused grouping. The fact that two universities in the top 20 had mixtures of activities most strongly related to the (Weaker External Entrepreneurial Income generating Activities) Indifferent grouping, however, also highlights the complexity of this issue.

Of the 50 universities with a positive score, the 16 Broad universities also have a lower average ranking than the 27 Ambidextrous universities. Interestingly, the Focused universities sit between these two groups in terms of average rankings, though they only have five universities in the top 50, and the differences in average rankings are not statistically significant at the 5\% level. 
Using these broad groups also allows us to contrast with previous approaches, which illustrate interesting and important differences. For example, compared with the approach of HewittDundas (2012), whilst there is a concentration of the old research-intensive/high researchintensive universities from the Russell Group in the Ambidextrous grouping (with 15 of the 24 universities coming from the Russell Group), there are another seven in the Broad universities grouping (of the total of 16), one in the Focused group and even one in the Indifferent group, that would be characterised as having a weak KT-generating mix of activities.

In comparison with Fuller et al. (2018), the index of overall rankings is also strongly but not overwhelmingly correlated, both with the entrepreneurial university index $(0.66)$ and the enterprising university index (0.71). This suggests that the approach used in this study is generally consistent with previous studies using different techniques, but is also able to provide additional novel information in relation to different strategic foci that underlie the rankings.

\subsection{The relationship between specific university models/archetypes and university regional economic development policy}

In answering RQ4, both means tests and Tamhane tests were used to compare the university models/archetypes in relation to their strategic priorities with regards to regional economic development policy. Specifically, we examined differences in relation to the university model/archetype mean scores for their top three Selected Strategic Priorities of UK universities related to Entrepreneurial/Innovation Ecosystems identified in HE-BCI Report (2017), in terms of widening participation, graduate retention in the local region, knowledge transfer, research collaboration with industry, incubator provision, local partnership development, regional skill needs, national skill needs, and commercialisation. The results indicate that universities in the Indifferent grouping, with relatively Weak External Entrepreneurial Income Generating Activities, are significantly (at the 5\% level) more strategically focused on the types of regional 
economic development-related activities that Morgan (2002) conceptualized as outreach in nature, in terms of human (social) capital development, than the model/archetype they are most often compared to, the Research university group (with an IP and spin-off focus). The differences between the Research, Broad, and Focused groups, whilst existing across a range of strategic priorities, were not found to be statistically significant.

More generally, the results support the view that simple dichotomies between 'elite' and 'outreach' universities (Morgan, 2002), low research-intensive/high research-intensive (Hewitt-Dundas, 2012), or Entrepreneurial/Enterprising (Fuller et al., 2018) are too simplistic. For example, relatively speaking, the Focused grouping have similar regional economic development policies to the Indifferent group in terms of widening participation and developing local partnerships, whilst for the Broad grouping, these similarities to the Indifferent grouping are pertain to graduate retention and regional skills. This study therefore suggests that there are at least three different groupings of what have been described in other studies as entrepreneurial universities (which includes those identified in the Hewitt-Dundas (2012) study as elite, but also other universities not identified as such in that study). These three different groupings, however, engage in distinct KT portfolios of activities, with subtly different mixtures of regional economic development priorities, the fourth grouping much more focused on outreach-related activities.

\section{Conclusions}

The present study examined the portfolio of KT activities in UK universities, creating an index and ranking of the universities. More importantly, it identified specific groupings or strategic profiles of universities defined by different combinations and strengths of the individual KT activities from which the overall rankings are derived. 


\subsection{Overall synthesis of research aims and findings}

The aim of this paper was to examine KT activities and also to group universities into KT "types", allowing universities and policymakers to better develop and measure clearer KTstrategies. The findings showed that the variables differing most among universities are Chargeable events, CPD-CE, and Collaborative research. It also showed that there are two distinct groups of activities based around CPD-Chargeable Events and Collaborative activities. Four distinct KT university "types" were also found to exist (Focused, Broad, Ambidextrous and Indifferent). Lastly, whilst the Indifferent grouping was not focused on KT activities per se, it could be seen to contribute to the economy through its greater focus on human (social capital) development.

\subsection{Implications for theory}

The contribution to knowledge concerning the KT activities of universities has been built by extending the existing literature (including that on entrepreneurship literature focused on university activities specifically and the Entrepreneurial university more broadly) on university archetypes and rankings (most notably Morgan, 2002; Hewitt-Dundas, 2012; Abreu et al., 2016, Fuller et al., 2018) through more detailed analysis of the range of university KT activities. The implications for theory are that simple dichotomous approaches are unsuitable, given the existence of at least three different groupings, of what have been described in other studies as entrepreneurial universities, with the fourth grouping focussing much more on outreach-related activities. This extends our understanding of universities activities as they relate to their own entrepreneurial activities (e.g. as entrepreneurial universities) but also in terms of archetypes more focused on outreach activities, which may still be of relevance in supporting entrepreneurial activity in the wider economy. 


\subsection{Implications for practice}

In addition, the use of this PROMETHEE-based approach contributes to method by allowing for a more nuanced definition of university KT than before, by simultaneously evaluating its overall strength, range, focus, and combination, thus allowing identification of the strategic profile of universities through their KT portfolios. The implications of the findings for key stakeholders for practice include a potential need for government higher education policy to take the different university archetype mixes that exist in a region into account when considering how best higher education can support regional policy goals. Importantly this includes supporting regional policy goals with regards to entrepreneurship, both of the university itself, and also of the wider economy, given that different university archetypes will be of more relevance to each.

\subsection{Limitations of the study and future research}

This research has a number of limitations. First, this study is based on one year of data, and a more longitudinal approach would be valuable, as Cesaroni and Piccaluga (2016) have demonstrated in the Italian context. Second, this study is within the UK context only, and research into a range of international contexts would also help develop this area. Third, whilst the paper has been able to map the KT activities universities focused on, the individual-level university reasons that might explain these results have not been analysed, allowing rich opportunities for understanding underlying strategies in future research. Fourth, the insights from the data are based on a cross-sectional analysis of those universities which currently generate income from KT. This means, therefore, that this approach is not able to evaluate longitudinal transitional processes towards more entrepreneurial universities, particularly in cases where there is no substantial income from the analysed activities. Nor has a detailed evaluation of the university's regional economic context been undertaken. More in-depth 
analysis of the factors underlying universities' strategic choices and their regional contexts would therefore seem to be the most fruitful areas for future research.

\subsection{Concluding Comments}

This research provides a more nuanced analysis, measuring the third mission as a range of important KT-activities. Third-mission strategies typically struggle to be accepted as a valuecreating activity, research previously focusing on more traditional measures of KT activity income generation. The third mission, however can have important spillover employment and innovation capacity effects within the regions, and can further influence student university preference and retention, making it important to both universities and policy makers. As an additional implication of the research, the partially compensatory and other qualities of PROMETHEE, in conjunction with GAIA, can potentially offer policymakers and universities a strong tool for measuring KT-activities, and determining the efficacy of different KTstrategies. 


\section{Reference}

Abreu, M., Demirel, P., Grinevich, V. and Karatas-Özkan, M. (2016), "Entrepreneurial practices in research-intensive and teaching-led universities", Small Business Economics, Vol. 47 No. 3, pp. 695-717.

Abreu, M. and Grinevich, V. (2013), "The nature of academic entrepreneurship in the UK: Widening the focus on entrepreneurial activities", Research Policy, Vol. 42 No. 2, pp. 408-422.

Behzadian, M., Kazemzadeh, R.B., Albadvi, A. and Aghdasi, M. (2010), "PROMETHEE: A comprehensive literature review on methodologies and applications", European Journal of Operational Research, Vol. 200 No. 1, pp. 198-215.

Berbegal-Mirabent, J., Lafuente, E. and Solé, F. (2013), "The pursuit of knowledge transfer activities: An efficiency analysis of Spanish universities", Journal of Business Research, Vol. 66 No. 10, pp. 2051-2059.

Berbegal-Mirabent, J., Sánchez García, J.L. and Ribeiro-Soriano, D.E. (2015), "Universityindustry partnerships for the provision of R\&D services", Journal of Business Research, Vol. 68 No. 7, pp. 1407-1413.

Brans, J.-P. (1982), L'ingénierie de La Décision: L'élaboration d'instruments d'aide a La Décision, Université Laval, Faculté des sciences de l'administration.

Brans, J.-P. and Mareschal, B. (1994), "The PROMCALC \& GAIA decision support system for multicriteria decision aid”, Decision Support Systems, Vol. 12 No. 4-5, pp. 297310.

Brans, J.-P. and Mareschal, B. (2005), "PROMETHEE methods.”, in Figueira, J., Greco, S. and Ehrgott, M. (Eds.), Multiple Criteria Decision Analysis: State of the Art Surveys, Vol. 78, Springer Science \& Business Media.

Brans, J.-P. and Vincke, P. (1985), "Note-A Preference Ranking Organisation Method: (The PROMETHEE Method for Multiple Criteria Decision-Making)", Management Science, Vol. 31 No. 6, pp. 647-656.

Bronstein, J. and Reihlen, M. (2014), "Entrepreneurial university archetypes: A metasynthesis of case study literature", Industry and Higher Education, Vol. 28 No. 4, pp. 245-262.

Cesaroni, F. and Piccaluga, A. (2016), "The activities of university knowledge transfer offices: towards the third mission in Italy", The Journal of Technology Transfer, Vol. 41 No. 4, pp.753-777.

Charles, D., Kitagawa, F. and Uyarra, E. (2014), "Universities in crisis? - new challenges and strategies in two English city-regions", Cambridge Journal of Regions, Economy and Society, Vol. 7 No. 2, pp. 327-348.

Colyvas, J.A. (2007), "From divergent meanings to common practices: The early institutionalization of technology transfer in the life sciences at Stanford University", Research Policy, Vol. 36 No. 4, pp. 456-476.

Culkin, N. (2016), "Entrepreneurial universities in the region: the force awakens?", International Journal of Entrepreneurial Behavior \& Research, Vol. 22 No. 1, pp. 416.

Czarnitzki, D., Glänzel, W. and Hussinger, K. (2009), "Heterogeneity of patenting activity and its implications for scientific research", Research Policy, Vol. 38 No. 1, pp. 2634.

Day, A. and Fernandez, R. (2015), Strategies for Sustaining Growth of Income from Knowledge Exchange across Higher Education Institutions (HEIs) in the UK, National Centre for Universities and Business, available at: 
https://www.praxisunico.org.uk/sites/praxisunico.org.uk/files/NCUB_Strategies\%20f or\%20Sustaining\%20Growth\%20of\%20Income.pdf (accessed 3 June 2018).

D'Este, P. and Patel, P. (2007), "University-industry linkages in the UK: What are the factors underlying the variety of interactions with industry?", Research Policy, Vol. 36 No. 9, pp. 1295-1313.

Etzkowitz, H., Webster, A., Gebhardt, C. and Terra, B.R.C. (2000), "The future of the university and the university of the future: evolution of ivory tower to entrepreneurial paradigm", Research Policy, Vol. 29 No. 2, pp. 313-330.

Fini, R., Grimaldi, R., Santoni, S. and Sobrero, M. (2011), "Complements or substitutes? The role of universities and local context in supporting the creation of academic spinoffs", Research Policy, Vol. 40 No. 8, pp. 1113-1127.

Fuller, D., Beynon, M. and Pickernell, D. (2017), "Indexing third stream activities in UK universities: exploring the entrepreneurial/enterprising university", Studies in Higher Education, Vol. 0 No. 0, pp. 1-25.

Fuller, D. and Pickernell, D. (2018), "Identifying groups of entrepreneurial activities at universities", International Journal of Entrepreneurial Behavior \& Research, Vol. 24 No 1, pp.171-190.

Gourlay, L. and Stevenson, J. (2017), "Teaching excellence in higher education: critical perspectives", Teaching in Higher Education, Vol. 22 No. 4, pp. 391-395.

Guerrero, M. and Urbano, D. (2012), "The development of an entrepreneurial university", The Journal of Technology Transfer, Vol. 37 No. 1, pp. 43-74.

Guerrero, M., Urbano, D., Fayolle, A., Klofsten, M. and Mian, S. (2016), "Entrepreneurial universities: emerging models in the new social and economic landscape", Small Business Economics, Vol. 47 No. 3, pp. 551-563.

Gulbrandsen, M. and Slipersaeter, S. (2007), "The third mission and the entrepreneurial university model", Universities and strategic knowledge creation, 112-143.

Hayez, Q., De Smet, Y. and Bonney, J. (2012), "D-Sight: a new decision making software to address multi-criteria problems", International Journal of Decision Support System Technology (IJDSST), Vol. 4 No. 4, pp. 1-23.

HEFCE. (2017), Higher Education - Business and Community Interaction Survey 2015-16., Department for Business, Energy \& Industrial Strategy, pp. 1-41.

Hewitt-Dundas, N. (2012), "Research intensity and knowledge transfer activity in UK universities", Research Policy, Vol. 41 No. 2, pp. 262-275.

Huggins, R., Johnston, A. and Stride, C. (2012), "Knowledge networks and universities: Locational and organisational aspects of knowledge transfer interactions", Entrepreneurship \& Regional Development, Vol. 24 No. 7-8, pp. 475-502.

Hughes, A. and Kitson, M. (2012), "Pathways to impact and the strategic role of universities: new evidence on the breadth and depth of university knowledge exchange in the UK and the factors constraining its development", Cambridge Journal of Economics, Vol. 36 No. 3, pp. 723-750.

Iorio, R., Labory, S. and Rentocchini, F. (2017), "The importance of pro-social behaviour for the breadth and depth of knowledge transfer activities: An analysis of Italian academic scientists", Research Policy, Vol. 46 No. 2, pp. 497-509.

Ishizaka, A. and Nemery, P. (2011), "Selecting the best statistical distribution with PROMETHEE and GAIA”, Computers \& Industrial Engineering, Vol. 61 No. 4, pp. 958-969.

Ishizaka, A., Resce, G. and Mareschal, B. (2018), "Visual management of performance with PROMETHEE productivity analysis", Soft Computing, Vol. 22 No. 22, pp. 73257338. 
Johnson, M. T. (2020). The knowledge exchange framework: understanding parameters and the capacity for transformative engagement. Studies in Higher Education, 1-18.

Kitagawa, F., Barrioluengo, M.S. and Uyarra, E. (2016), "Third mission as institutional strategies: Between isomorphic forces and heterogeneous pathways", Science \& Public Policy, Vol. 43 No. 6, pp. 736-750.

Kalar, B. and Antoncic, B. (2015), "The entrepreneurial university, academic activities and technology and knowledge transfer in four European countries", Technovation, Vol. 36, pp. 1-11.

Lai, Y.-L. and Ishizaka, A. (2019), "The application of multi-criteria decision analysis methods into talent identification process: A social psychological perspective", Journal of Business Research, p. S0148296319304977.

Lambert, R. (2003), Lambert Review of Business-University Collaboration, HM Treasury, London, available at: http://www.hmtreasury.gov.uk/media//EA556/lambert_review_final_450.pdf (accessed 25 June 2018).

Magerman, T., Looy, B.V. and Debackere, K. (2015), "Does involvement in patenting jeopardize one's academic footprint? An analysis of patent-paper pairs in biotechnology", Research Policy, Vol. 44 No. 9, pp. 1702-1713.

Mareschal, B., De Smet, Y. and Nemery, P. (2008), "Rank reversal in the PROMETHEE II method: some new results", 2008 IEEE International Conference on Industrial Engineering and Engineering Management, IEEE, pp. 959-963.

Martin, B.R. (2012), "Are universities and university research under threat? Towards an evolutionary model of university speciation", Cambridge Journal of Economics, Vol. 36 No. 3, pp. 543-565.

Martin, L. M., Warren-Smith, I. and Lord, G. (2019), "Entrepreneurial architecture in UK universities: still a work in progress?", International Journal of Entrepreneurial Behavior \& Research, Vol. 25 No. 2, pp. 281-297.

Martinelli, A., Meyer, M., \& Von Tunzelmann, N. (2008). Becoming an entrepreneurial university? A case study of knowledge exchange relationships and faculty attitudes in a medium-sized, research-oriented university. The Journal of Technology Transfer, 33(3), 259-283.

Mason, C. and Brown, R. (2013), "Creating good public policy to support high-growth firms", Small Business Economics, Vol. 40 No. 2, pp. 211-225.

Miller, K., McAdam, M. and McAdam, R. (2014), "The changing university business model: a stakeholder perspective", $R \& D$ Management, Vol. 44 No. 3, pp. 265-287.

Molas-Gallart, J. and Castro-Martínez, E. (2007), "Ambiguity and conflict in the development of "Third Mission'indicators", Research Evaluation, Vol. 16 No. 4, pp. 321-330.

Morgan, B. (2002), "Higher education and regional economic development in Wales: an opportunity for demonstrating the efficacy of devolution in economic development", Regional Studies, Vol. 36 No. 1, pp. 65-73.

Mowery, D., Nelson, R., Sampat, B. and Ziedonis, A. (2015), Ivory Tower and Industrial Innovation University-Industry Technology Transfer before and after the Bayh-Dole Act, Stanford Business Books.

Nemery, P., Ishizaka, A., Camargo, M. and Morel, L. (2012), "Enriching descriptive information in ranking and sorting problems with visualizations techniques", Journal of Modelling in Management, Vol. 7 No. 2, pp. 130-147.

Olmos-Peñuela, J., Castro-Martínez, E. and D’Este, P. (2014), “Knowledge transfer activities in social sciences and humanities: Explaining the interactions of research groups with non-academic agents", Research Policy, Vol. 43 No. 4, pp. 696-706. 
Perkmann, M., Tartari, V., McKelvey, M., Autio, E., Broström, A., D’Este, P., Fini, R., et al. (2013), "Academic engagement and commercialisation: A review of the literature on university-industry relations", Research Policy, Vol. 42 No. 2, pp. 423-442.

Philpott, K., Dooley, L., O'Reilly, C. and Lupton, G. (2011), “The entrepreneurial university: Examining the underlying academic tensions", Technovation, Vol. 31 No. 4, pp. 161170.

Pittaway, L., Aissaoui, R., Ferrier, M. and Mass, P. (2019), "University spaces for entrepreneurship: a process model", International Journal of Entrepreneurial Behavior \& Research, Vol. ahead-of-print No. ahead-of-print. https://doi.org/10.1108/IJEBR-09-2018-0584

Ramos-Vielba, I., Sánchez-Barrioluengo, M. and Woolley, R. (2016), "Scientific research groups' cooperation with firms and government agencies: motivations and barriers", The Journal of Technology Transfer, Vol. 41 No. 3, pp. 558-585.

"Russell Group. Profile". (2015), , available at: https://www.russellgroup.ac.uk/ media/4997/profile-of-the-russell-group-of-universities.pdf (accessed 30 July 2019).

Sánchez-Barrioluengo, M. (2014), "Articulating the 'three-missions' in Spanish universities", Research Policy, Vol. 43 No. 10, pp. 1760-1773.

Schartinger, D., Schibany, A. and Gassler, H. (2001), "Interactive relations between universities and firms: Empirical evidence for Austria”, The Journal of Technology Transfer, Vol. 26 No. 3, pp. 255-268.

Secundo, G., Perez, S. E., Martinaitis, Ž. and Leitner, K. H. (2017), "An Intellectual Capital framework to measure universities' third mission activities", Technological Forecasting and Social Change, Vol. 123, pp. 229-239.

Sengupta, A. and Ray, A. (2017a), "University research and knowledge transfer: A dynamic view of ambidexterity in British universities", Research Policy, Vol. 46 No. 5, pp. 881-897.

Sengupta, A. and Ray, A. (2017b), "Choice of Structure, Business Model and Portfolio: Organizational Models of Knowledge Transfer Offices in British Universities", British Journal of Management, Vol. 28 No. 4, pp. 687-710.

Tofallis, C. (2008), "Selecting the best statistical distribution using multiple criteria", Computers \& Industrial Engineering, Vol. 54 No. 3, pp. 690-694.

Van Looy, B., Landoni, P., Callaert, J., van Pottelsberghe, B., Sapsalis, E. and Debackere, K. (2011), "Entrepreneurial effectiveness of European universities: An empirical assessment of antecedents and trade-offs", Research Policy, Vol. 40 No. 4, pp. 553564. 